\title{
Characteristics of Preschoolers with Lower Perceived Competence
}

\author{
Robert J. Coplan \\ Carleton University \\ Leanne C. Findlay \\ Carleton University
}

Larry J. Nelson

Brigham Young University - Provo, larry_nelson@byu.edu

Follow this and additional works at: https://scholarsarchive.byu.edu/facpub

Part of the Other Social and Behavioral Sciences Commons

\section{Original Publication Citation}

Coplan, R. J., *Findlay, L. C., \& Nelson, L. J. (2004). Characteristics of preschoolers with lower perceived competence. Journal of Abnormal Child Psychology, 32, 399-408.

\section{BYU ScholarsArchive Citation}

Coplan, Robert J.; Findlay, Leanne C.; and Nelson, Larry J., "Characteristics of Preschoolers with Lower Perceived Competence" (2004). Faculty Publications. 4670.

https://scholarsarchive.byu.edu/facpub/4670

This Peer-Reviewed Article is brought to you for free and open access by BYU ScholarsArchive. It has been accepted for inclusion in Faculty Publications by an authorized administrator of BYU ScholarsArchive. For more information, please contact ellen_amatangelo@byu.edu. 


\title{
Characteristics of Preschoolers With Lower Perceived Competence
}

\author{
Robert J. Coplan, ${ }^{1,3}$ Leanne C. Findlay, ${ }^{1}$ and Larry J. Nelson ${ }^{2}$
}

Received September 16, 2003; revision received January 28, 2004; accepted February 10, 2004

\begin{abstract}
The goal of the present study was to identify preschool children with "age-inappropriate" less positive self-perceptions, and to explore their parental and peer relationships as compared to their classmates with "age normal" self-perceptions. Participants were $n=127$ preschool children $\left(M_{\text {age }}=54.98\right.$ mos., $S D=8.21$ ). Data were collected from multiple sources including parental ratings, child selfreports, and teacher ratings. Results indicated that as compared to their peers, children with less positive self-perceptions demonstrated more internalizing problems (i.e., loneliness, social-withdrawal), were more excluded by peers, and had mothers with less positive parenting styles. Results are discussed in terms of the implications of poorer self-perceptions in early childhood.
\end{abstract}

KEY WORDS: self-concept; perceived-competence; preschool; social adjustment.

Children and adolescents who think poorly about themselves are considered at risk for a myriad of negative outcomes, including depression (e.g., Harter \& Jackson, 1993), eating disorders (e.g., Heatherton \& Baumeister, 1991), and suicidal ideation (e.g., Harter, Marold, \& Whitesell, 1992). Conversely, positive self-perceptions have been found to be associated with favorable outcomes such as academic achievement (e.g., Marsh, Ellis, \& Craven, 2002) and peer acceptance (e.g., Boivin \& Begin, 1989). Whereas significant attention has been given to identifying the developmental origins and concomitants of negative self-perceptions in late childhood and adolescence (for a review see Harter, 1998), the correlates of self-concept in early childhood (i.e., ages 4-5 years) have received relatively little attention.

Young children appear to be able to make concrete cognitive representations about the self (e.g., Damon \& Hart, 1982; Griffin, 1992; Harter \& Pike, 1984; Marsh, Craven, \& Debus, 1991; Siegler, 1991; Verschueren, Marcoen, \& Schoefs, 1996). However, the cognitive representations of young children differ from those of older

\footnotetext{
${ }^{1}$ Carleton University, Ottawa, Ontario, Canada.

${ }^{2}$ Brigham Young University, Provo, Utah.

${ }^{3}$ Adddress all correspondence to Robert J. Coplan, Ph.D., Department of Psychology, Carleton University, 1125 Colonel By Drive, Ottawa, Ontario, Canada K1S 5B6; e-mail: robert_coplan@carleton.ca.
}

children. Specifically, self-representations in early childhood are consistent with the cognitive abilities of this age period in that they are (a) typically all-or-none in structure (Fischer, Hand, Watson, Van Parys, \& Tucker, 1984); (b) centered around concrete and observable abilities, activities, and possessions (Fischer, 1980; Griffin, 1992; Harter, 1996); and (c) often inaccurate, particularly in terms of being unrealistically positive (Harter \& Pike, 1984). This tendency for young children to view themselves in a very positive light is not only developmentally "normal," but possibly beneficial as well. For instance, Harter (1990) noted that positive self-perceptions might serve to motivate children toward greater levels of mastery. In other words, positive self-perceptions can promote growth. Therefore, it may be important to identify children who view themselves negatively, or even realistically, at an age when it is developmentally "atypical" to do so. The primary goal of the present research was to identify characteristics that distinguish preschool children with poorer self-perceptions from the majority of their peers who tend to perceive themselves in an extremely positive light.

\section{Correlates of Self-Perceptions in Early Childhood}

It has long been posited that social interaction is important for the normal development of the self-system. For 
example, Mead (1925, 1934) and Cooley (1902) believed that the self originates from social interaction with significant others. Such social exchanges allow the child to gain an understanding of the self as both subject and object. Cooley (1902) used the metaphor of a social "lookingglass" to explain how the self develops. He believed that individuals construct a picture of themselves based on the ways that others perceive them. In other words, individuals look to others for information about themselves (e.g., verbal reactions and comments, nonverbal reactions and expressions). The process of looking to others for information about oneself represents his/her "looking-glass self."

More recently, it has been suggested that children's perceptions of how they are viewed by others largely affect feelings toward the self (Cole, Jacquez, \& Maschman, 2001; Harter, 1998). For instance, Rudolph, Hammen, and Burge (1995) reported that children's self-perceptions were closely tied to their relationships with both family and peers. Both social interaction and feedback from significant others (e.g., parents, peers) are believed to be involved in the formation of self-perceptions. In the present study, we anticipated that young children with ageinappropriate less positive self-perceptions would demonstrate "poorer" relations with both peers and parents.

\section{Peer Relations and Self-Perceptions}

There is an accumulating literature linking poor peer relations with more negative self-perceptions in middle and later childhood. Results from research with schoolaged children have indicated negative associations between self-perceptions and various indices of peer relation difficulties, including peer rejection, loneliness, social anxiety, and social withdrawal (e.g., Fordham \& Stevenson-Hinde, 1999; Hymel, Bowker, \& Woody, 1993; Hymel, Rubin, Rowden, \& LeMare, 1990; Qualter \& Munn, 2002).

Boivin and Hymel (1997) suggest that there are multifaceted processes leading from social difficulties with peers to negative self-perceptions, which may include both direct and indirect associations. For example, children who are rejected by their peers may have a pessimistic view of their social world and thus interpret their social situation more negatively. More indirectly, children's social behaviors (i.e., social withdrawal) may elicit negative feedback from peers, which in turn have harmful effects on developing self-perceptions (Hymel et al., 1990, 1993).

The relation between self-perceptions and aspects of children's peer relations in preschool remains underexplored. Verschueren et al. (1996) reported that as compared to their peers, 5-year-old children with more neg- ative self-perceptions were rated by teachers as less socially accepted and as having more school adjustment difficulties. In a follow-up longitudinal study, Verschueren, Buyck, and Marcoen (2001) found that these same children felt less socially accepted, had more negative global self-perceptions, and were rated by their teachers as more poorly adjusted and less independent at age 8 years. These results suggest that poorer self-perceptions in early childhood have concurrent and predictive associations with children's social functioning. In the present study, we sought to explore a wider range of peer relation difficulties. It was hypothesized that children with less positive selfperceptions would be more anxious with peers, sociallywithdrawn, lonely, and excluded by peers as compared to their counterparts with age-normative self-perceptions.

It should also be noted, however, that not all children with poor peer relations experience negative selfperceptions. For example, results from previous research with school-aged children have indicated that aggressive children, who are often rejected by their peers, do not typically report feeling poorly about themselves (Hymel et al., 1990, 1993; Patterson, Kupersmidt, \& Griesler, 1990; see Edens, 1999, for a review). In fact, aggressive children tend to overestimate their competencies (Hughes, Cavell, \& Grossman, 1999; Hymel et al., 1993). Aggressive children may be unable to identify, or profess, their inadequacies, and thus overestimate their abilities. In this way, they are like their younger peers in that they inflate their own competencies. However, research with preschool children in this area remains limited. Given the findings with older children, in the present study, it was hypothesized that children with less positive self-perceptions would not differ from their peers in terms of aggression.

\section{Parenting Styles and Self-Perceptions}

Parenting socialization practices are seen as "critical to the development of many self processes" (Harter, 1998, p. 583). Children as young as 2 years of age seem to be able to evaluate their own behavior as a function of parental reactions (Stipek, Recchia, \& McClintic, 1992). From an attachment perspective (e.g., Bowlby, 1969), a working model of self can only be considered within the context of the caregiver-infant relationship from which it emerged. In support of this notion, secure mother-child attachment has been related to a positive representation of the self (e.g., Cassidy, 1988; Verschueren et al., 1996; Verschueren \& Marcoen, 1999).

In the present study, our focus was on the relation between self-perceptions and parental disciplinary styles. A parenting style characterizes a constellation of parenting 
behaviors, which creates a pervasive interactional climate over a broad range of contexts and situations (Coplan, Hastings, Lagace-Seguin, \& Moulton, 2002; Darling \& Sternberg, 1993; Mize \& Pettit, 1997). Of particular interest for the present study were the authoritarian and permissive parenting styles (e.g., Baumrind, 1989, 1997). The authoritarian parenting style involves power assertion without warmth, nurturance, or two-way communication. In contrast, permissive parents do not firmly enforce rules and tend to have a "laissez faire" attitude towards childrearing.

Both authoritarian and permissive parenting styles are generally considered as less advantageous for many aspects of child development (Baumrind, 1978; Bugental \& Goodnow, 1998; Maccoby \& Martin, 1983) and have been associated with poorer self-perceptions among schoolaged children and adolescents (see Harter, 1999, for a recent review). Coopersmith (1967) reported that parents of school-age children with more negative self-perceptions were less approving, accepting, affectionate, and involved, and more likely to use coercive discipline.

The notion that children of parents who are low in care/warmth and high in control show lower self-esteem has received some empirical support (Graybill, 1978; Herz \& Gullone, 1999; Parish \& McCluskey, 1992). For example, Lamborn, Mounts, Steinberg, and Dornbusch (1991) reported that young adolescents of authoritarian and neglectful parents had lower perceived competence and selfreliance as compared to adolescents of authoritative (i.e., warm and responsive) parents. In a follow-up study, Steinberg, Lamborn, Darling, Mounts, and Dornbusch (1994) found that these differences were still apparent 1 year later. However (and somewhat surprisingly), we were unable to find any previous empirical research directly exploring the relation between parenting styles and self-perceptions in preschoolers. In the present study, it was hypothesized that preschoolers with less positive perceived competencies would have mothers who were more negative in their disciplinary styles (i.e., authoritarian, permissive).

\section{The Present Study}

Given that it is developmentally atypical for young children to have self-representations that are anything but unrealistically positive (Harter, 1990, 1999; Harter \& Pike, 1984; Piaget, 1932), the purpose of this research was to explore the characteristics of children with atypically less positive self-perceptions. Social interaction and positive feedback seem to play important functions in the development of the self-system. Therefore, young children with less positive self-perceptions were expected to be those who do not have positive social interactions and/or who receive negative feedback from peers and parents.

Drawing upon the extant research reviewed above, it was hypothesized that as compared with their more typical peers, children with less positive self-perceptions would demonstrate problematic peer relations (i.e., greater anxiety, social-withdrawal, loneliness, and peer exclusion - but not aggression) and have mothers with more negative parenting styles (i.e., authoritarian, permissive). Verschueren et al. (1996) suggested that the relation between young children's self-perceptions and social behaviors might be accounted for by the confounding effect of vocabulary. In the present study, child vocabulary was assessed and controlled for statistically in all analyses.

\section{METHOD}

\section{Participants}

Participants in this study were 127 children (66 boys, 61 girls) between the ages of 42 and 72 months ( $M_{\text {age }}=$ 54.98 mos., $S D=8.21$ ). The children were attending local preschools and childcare centers in and around Ottawa, Canada. The sample was primarily White (78\%), with a variety of other ethnic groups also represented (9\% Asian, 2\% Black, 2\% Hispanic, and 5\% other). The sample was also of varied socioeconomic status. Approximately $17 \%$ of mothers and $16 \%$ of fathers had completed high school, $69 \%$ of mothers and $62 \%$ of fathers had a college/university degree, and $14 \%$ of mothers and $18 \%$ of fathers had a graduate level degree. Unfortunately, information on the employment status and income of parents was not available.

\section{Measures}

\section{Perceived Competence}

Children were interviewed individually by a trained female research assistant. The first part of the interview comprised the Pictorial Scale of Perceived Competence and Social Acceptance for Young Children (PSPCSA; Harter \& Pike, 1984). The PSPCSA is one of the most commonly cited and extensively employed tools to assess the self-concept of children ages 4-7 years (see Byrne, 1996; Fantuzzo, McDermott, Manz, Hampton, \& Burdick, 1996).

This 24-item instrument contains two subscales designed to assess young children's perceived competence 
(physical and cognitive) and perceived acceptance (peer and maternal). In order to reduce children's tendency to give socially desirable responses, a structured-alternative response format is employed when presenting the items. Children are presented with a picture plate accompanied by two statements related to the picture. The child is asked to identify the child he/she is most like. The child is then asked if they are "a little bit like that child," or "a lot like that child." In this regard, each item is rated on a 4-point scale. Harter and Pike (1984) reported the factor structure of the PSPCSA in a sample of 255 four to seven year-old children, and demonstrated acceptable subscale reliabilities (ranging from .75 to .89). Indications of convergent, discriminant, and predictive validity were also provided.

The perceived competence subscale was used to identify children with atypically less positive self-perceptions. Self-judgment with respect to competence is a more direct type of self-appraisal than is acceptance by others, which depends on the young child's view of others and on the child's understanding of the role of social skills in being accepted by others. In support of this notion, Klein and Magill-Evans (1998) reported that the competence subscale of the PSPCSA was more stable over time than the acceptance subscale. Moreover, whereas other selfconcept measures have been criticized for imposing high language demands on children, the competence subscale of the PSPCSA has been shown to be linguistically acceptable for young children (Jambunathan \& Norris, 2000).

Following Harter and Pike (1984), the perceived competence subscale was created by averaging the 12 items assessing perceived physical and cognitive competencies, yielding a summary score measured on the original 4-point Likert scale. In the current sample, Cronbach's alpha for the perceived competence scale was $\alpha=.68$.

\section{Loneliness}

The next part of the interview consisted of the Loneliness and Social Dissatisfaction Questionnaire for Young Children (Asher \& Wheeler, 1985; Cassidy \& Asher, 1992). Children are asked to respond accordingly with "yes," "no," or "sometimes" to 24 items related to loneliness (e.g., "Do you have kids to play with at school?"). This measure has been used in several studies with elementary school children and has demonstrated excellent psychometric properties, consistent factor structure across samples, high internal consistency, and good test-retest reliability (see Asher, Parkhurst, Hymel, \& Williams, 1990; Terrell-Deutsch, 1999). In the current sample, items were averaged to create an aggregate measure of loneliness as measured on the original 3-point Likert scale ( $\alpha=.76)$. Although this measure was originally designed for use with somewhat older children, the Loneliness and Social Dissatisfaction Questionnaire for Young Children has been used successfully with children as young as 5 years of age (e.g., Ladd \& Burgess, 1999). Ladd and Coleman (1997) found moderate stability of loneliness from the beginning to the end of the kindergarten school year. In this same study, negative associations were reported between loneliness and early school adjustment.

\section{Vocabulary}

A second individual child interview was conducted (typically 3-4 days later) and included the ExpressiveOne-Word-Picture-Vocabulary Test (EOWPVT, Gardner, 1990). This test was developed to assess expressive vocabulary in children, and has been used extensively in previous research (e.g., Evans \& Wodar, 1997; Ukrainetz \& Blomquist, 2002; Wiesner \& Beer, 1991). Children are presented with a series of line drawings that are graded by increasing difficulty, and are asked to say what the picture represents in one word. Gardner (1990) reported excellent psychometric properties of the EOWPVT, and presented norms for children aged 2-12 years based on test results from a sample of 1118 children. Children's raw scores are standardized using these predetermined norms (standardized to have a mean of 100 and $S D$ of 15) to create a summary score of expressive vocabulary.

\section{Teacher Ratings of Child-Peer Relations}

Teachers completed the Child Behavior Scale (CBS, Ladd \& Profilet, 1996), a 35-item scale designed to assess preschool children's adjustment with peers. This scale has good psychometric properties and has been used often in recent years to assess children's socioemotional behaviors in the preschool and kindergarten classroom (e.g., Coplan \& Armer, in press; Ladd \& Burgess, 1999).

Of particular interest for the present study were the subscales of excluded by peers ( 7 items, $\alpha=.86$, e.g., "peers refuse to let this child play with them"), asocial with peers (6 items, $\alpha=.90$, e.g., "solitary child"), anxious with peers ( 4 items, $\alpha=.77$, "tends to be fearful or afraid of new things or new situations"), and aggressive with peers ( 7 items, $\alpha=.91$, e.g., "kicks, bites, or hits other children").

\section{Parenting Styles}

Mothers completed the Parenting Styles and Dimensions Questionnaire (PSDQ, Robinson, Mandleco, Olsen, \& Hart, 2001; Wu, Robinson, Yang, Hart, Olsen, \& Porter, 
2002), a 32-item scale designed to assess various parenting styles. The PSDQ is a shortened version (using the highest loading items on each factor) of the 56-item Parenting Practices Questionnaire (PPQ), originally developed by Robinson, Mandelco, Olsen, and Hart (1995). The newly developed PSDQ and the original PPQ have both demonstrated excellent psychometric properties, and have been associated in a conceptually consistent manner with measures of parenting goals and attributions, as well as relevant child outcomes (e.g., Coplan et al., 2002; Robinson et al., 1995; Wu et al., 2002).

Of particular interest for the present study were the subscales of authoritarian parenting (7 items, $\alpha=.76$ ), with items related to verbal hostility (e.g., "yells and shouts when child misbehaves"), physical coercion (e.g., "spanks when child is disobedient") and nonreasoning (e.g., "takes away privileges with little if any explanations"), permissive parenting ( 5 items, $\alpha=.67$ ), and items related to lack of follow through (e.g., "threaten my child with punishment more often than actually giving") and self-confidence (e.g., "find it difficult to discipline child").

\section{RESULTS}

\section{Creation of Self-Perception Groups}

The mean score on the Perceived Competence subscale was $3.25(S D=.42)$. Similar to the findings of Harter and Pike (1984), the data were skewed in the direction of positive judgments. Children with scores one standard deviation or more below the mean were placed in the less-positive-self-perceptions of competence group ( $n=16, M=2.55, S D=.21 ; 7$ males, 9 females) and the rest of the sample formed the comparison group with "normal" self-perceptions of competence $(n=111, M=$ $3.35, S D=.34 ; 59$ males, 52 females). Because the data were skewed in the direction of positive judgments, and based on theory and research suggesting that it is "normal" at this age to have overinflated self-perceptions, only a small portion of the sample was expected to have scores considered "low" for this age.

\section{Differences Between Self-Perception Groups}

\section{Demographic Variables}

Results from preliminary analyses indicated that the gender composition of the self-perception groups did not differ significantly from expected values $\left(\chi^{2}=.49, n s\right)$. Similarly, the ethnic composition of each group (White vs. other) was also comparable $\left(\chi^{2}=.97, n s\right)$. As well, the two self-perception groups did not differ significantly in terms of child age $(t(125)=-1.22, n s)$ or parental education $(t(125)=.15, n s)$. However, children with lower perceived-competence did demonstrate significantly lower vocabulary scores $(M=98.81, S D=18.21)$ than the comparison group $(M=110.41, \quad S D=18.78$; $t(123)=-2.31, p<.05)$. As a result, vocabulary was statistically controlled for in all subsequent analyses.

\section{Peer Relations}

A multivariate analysis of covariance (MANCOVA) was performed (with vocabulary serving as a covariate) to explore differences between poorer self-perception and comparison children on variables related to peer relationship difficulties (i.e., anxious with peers, asocial with peers, excluded by peers, loneliness). Results indicated a significant main effect of Self-Perception Group $(F(4,115)=2.52, p<.05)$. Examination of subsequent univariate analyses indicated a significant effect of SelfPerception Group for asocial with peers $(F(1,118)=$ $4.11, p<.05)$, anxious with peers $(F(1,118)=5.23$, $p<.05)$, and peer exclusion $(F(1,118)=4.36, p<$ $.05)$, whereas the results for loneliness approached significance $(F(1,118)=3.25, p<.08)$. Means and standard deviations are displayed in Table I. As compared to their peers, children with less positive self-perceptions were rated by teachers as significantly more asocial, anxious, excluded by peers, and tended to report being more lonely.

Results from univariate analyses did not indicate a significant effect of Self-Perception Group for teacher ratings of aggression with peers $(F(1,118)<1, n s)$. Thus, children in the less positive self-perceptions group did not differ significantly from their comparison peers in terms of aggression (see Table I).

Table I. Self-Perception Group Means (Standard Deviations) for Indices of Relations With Peers and Parents

\begin{tabular}{|c|c|c|}
\hline & $\begin{array}{l}\text { Less positive-self } \\
\text { perceptions }\end{array}$ & $\begin{array}{l}\text { Age-normal- } \\
\text { self-perceptions }\end{array}$ \\
\hline \multicolumn{3}{|l|}{ Peer variables ${ }^{a}$} \\
\hline Anxious with peers & $1.55(.36)^{* *}$ & $1.32(.42)$ \\
\hline Asocial with peers & $1.56(.58)^{* *}$ & $1.27(.29)$ \\
\hline Loneliness & $1.67(.26)^{*}$ & $1.49(.35)$ \\
\hline Excluded by peers & $1.37(.63)^{* *}$ & $1.14(.33)$ \\
\hline Aggressive with peers & $1.39(.58)$ & $1.34(.43)$ \\
\hline \multicolumn{3}{|l|}{ Maternal variables ${ }^{b}$} \\
\hline Authoritarian parenting & $1.81(.43)^{* *}$ & $1.56(.30)$ \\
\hline Permissive parenting & $2.26(.35)^{* *}$ & $1.96(.46)$ \\
\hline
\end{tabular}


Parenting Styles

A second MANCOVA (with vocabulary again serving as a covariate) was conducted to explore differences between poorer self-perception and comparison children in terms of variables related to parenting (i.e., authoritarian, permissive). Results again indicated a significant main effect of Self-Perception Group $(F(2,119)=3.71$, $p<.05)$. Examination of subsequent univariate analyses indicated a significant effect of Self-Perception Group for authoritarian $(F(1,120)=6.31, p<.05)$ and permissive parenting $(F(1,120)=4.00, p<.05)$. As compared to their peers, children with less positive self-perceptions had mothers who reported significantly more authoritarian and permissive parenting styles (see Table I).

\section{DISCUSSION}

Positive self-perceptions are typical in early childhood (Harter, 1990, 1999; Harter \& Pike, 1984; Piaget, 1932). The purpose of this research was to explore the characteristics of children who viewed themselves more negatively, as compared to the majority of their peers who perceived themselves in an extremely positive light. Social interaction and positive feedback seem to play an important role in the development of the self-system; therefore, indices of peer relations and parental disciplinary style were investigated.

The results of the study largely supported the hypotheses. As expected, as compared to their counterparts with age-normal self-perceptions, young children with less positive self-perceptions were rated by teachers as being more socially anxious, socially withdrawn, and excluded by peers (but not more aggressive); self-reported being more lonely; and had mothers who rated themselves as more authoritarian and permissive in their parenting styles. These differences were evident even when controlling for group differences in child vocabulary level. Thus, young children with less positive self-perceptions appear to be exposed to negative images in the social "lookingglass" (Cooley, 1902), as "reflected" in their experiences with both peers and parents. Moreover, the present results suggest that even in early childhood, a more negative sense of self is a marker variable for psychosocial maladjustment.

\section{Peer Relations and Self-Perceptions}

In many regards, these findings mirror results found in studies with older children which have linked self- perceptions with various internalizing difficulties, including anxiety and social withdrawal (Boivin \& Hymel, 1997; Hymel et al., 1993). For instance, concurrent relations have been found between low self-perceptions and social withdrawal, loneliness, and anxiety (e.g., Asendorpf, 1993; Fordham \& Stevenson-Hinde, 1999; Hymel et al., 1990; Rubin, 1985). The current results demonstrated that even younger children with less positive self-perceptions were reported to be significantly more asocial with peers and felt greater anxiety with their peers. These findings also suggest that the relation between low self-perceptions and loneliness can be applied to a younger cohort of children.

Our results are in line with the work of Verschueren et al., who found that children with more positive selfrepresentations (as indicated by feelings of competence) demonstrated more frequent behavioral manifestations of high self-esteem at age 5 years (Verschueren et al., 1996) and were found to be better adjusted and more independent at age 8 than were their counterparts with poorer self-perceptions (Verschueren et al., 2001). The current study extends this research by including more specific measures of relations with peers, as well as adding the component of parental style. Indeed, children who felt less competent were more excluded by peers and reported more loneliness. These findings are consistent with previous research results with older children (e.g., Boivin \& Hymel, 1997), and support the contention that children interpret peer rejection as negative feedback, thus lowering perceptions of competencies. Apparently, being excluded by their peers may elicit negative feelings of competence even in preschool children. Taken together, these results suggest that children who have atypically low selfperceptions are at an early risk for a range of internalizing problems and social difficulties.

Given that the present study was correlational in nature, it is not possible to make any firm conclusions regarding the causal process that may explain the links found between less positive self-perceptions, indices of internalizing problems, and peer rejection. Various conceptual mechanisms are plausible. For example, negative selfperceptions may influence children's social behaviors, such that children who feel negatively about themselves become less likely to enter a social situation and/or feel greater anxiety in social settings. This in turn might lead to increased peer rejection. Conversely, feeling anxious with peers might be interpreted by the child as a lack of competence. These feelings would be directly reinforced by being excluded by peers, thus leading to a decrease of perceived competence.

Most likely, a transactional relation exists between self-perceptions, internalizing problems, and peer 
rejection (Boivin \& Hymel, 1997). For example, children who feel negatively about themselves may refrain from social interaction with peers. Accordingly, withdrawn children may tend to be excluded by their peers (Younger, Gentile, \& Burgess, 1993). Asocial behaviors may elicit negative feedback from peers, which in turn have harmful effects on developing self-perceptions (Hymel et al., 1990, 1993). Withdrawn-rejected children may acquire a more negative outlook on their social abilities, which further fosters the development of negative self-perceptions (Boivin \& Hymel, 1997). This could create a negative degenerative cycle whereby poorer self-perceptions lead to even more social withdrawal, which invites more peer rejection, which in turn promotes loneliness, social anxiety, and even more negative self-perceptions.

\section{Self-Perceptions and Aggression}

It is important to note that not all indices of peer relationship difficulties were associated with less positive self-perceptions. Consistent with predictions, children with less positive self-perceptions were not found to differ from their peers in terms of aggressive behavior. As noted earlier, results from previous research with middleschool-aged children has suggested that aggressive children do not typically experience less positive than normal self-perceptions (Hymel et al., 1990; Patterson et al., 1990).

Despite the fact that children who engage in various forms of aggression tend to be rejected by their peers even in early childhood (e.g., McNeilly-Choque, Hart, Robinson, Nelson, \& Olsen, 1996), this negative feedback from peers does not appear to adversely affect their self-perceptions. Aggressive behavior has been found to be negatively associated with perspective-taking abilities (Minde, 1992), which may include the inability to perceive and interpret others' reactions to their aggressive behavior. Thus, aggressive children may not accurately perceive being rejected by their peers. As a result, their self-perceptions may not be as adversely affected. In comparison, withdrawn children may realize that they are being rejected, being more sensitive to the social situation, and thus their self-perceptions may be impacted negatively. This argument lends credence to the hypothesis that social behavior influences peer feedback, which in turn has an impact on self-perceptions.

\section{Parenting and Self-Perceptions}

Results from the current study also provide additional support for the notion that children's self-perceptions are closely tied to their relationships with both family and peers (e.g., Rudolph et al., 1995). Children with less positive self-perceptions were found to have mothers characterized by "less optimal" parenting styles. These findings correspond with previous research results indicating that parents of older children with less positive selfperceptions tend to be less affectionate and involved, and inconsistent in the enforcement of rules (see Coopersmith, 1967; Herz \& Gullone, 1999; Lamborn et al., 1991). Our results provide some of the first empirical support for the notion that even at an early age, certain parental styles are negatively related to child self-perceptions.

However, as described previously, the directionality of the relations found in the present study remain somewhat unclear. For example, it is likely that parenting styles directly influence the self-perceptions of young children. Positive family environments are thought to foster the development of positive social skills and promote social opportunities, leading to higher self-perceptions (Lamborn et al., 1991). Positive parenting styles are also speculated to provide a more positive environment for the child, such that warmth and nurturance create positive feelings of self (Harter, 1998). Authoritarian and permissive styles reflect more negative approaches, including less affection, acceptance, and approval. Children who experience negative feedback (i.e., the harsh authoritarian style) or a general lack of support (permissive style) have no feedback to create positive feelings of self-competence, but rather may be more realistic or pessimistic about their competencies.

It is also possible that child characteristics related to less positive self-perceptions evoke more negative parental responses. For example, there is some evidence to suggest that temperamentally "difficult" children are more likely to elicit negative reactions from parents (Barron \& Earls, 1984; Carson \& Bittner, 1994; Coplan, Bowker, \& Cooper, 2003; Rutter, 1987; Thomas \& Chess, 1977). Moreover, negative child behaviors are particularly likely to elicit harsh parental responses among mothers who already demonstrate an overall tendency to be more authoritarian (Coplan et al., 2002). Clearly, longitudinal studies are required to further explore these mechanisms.

\section{Limitations and Implications for Future Research}

Taken together, the present findings suggest that children with less positive self-perceptions demonstrate a negative pattern of relations with both peers and parents. Given that there is evidence that negative self-perceptions are stable from early to middle childhood (Verschueren et al., 1996), there appears to be good reason to be concerned about young children who do not possess the 
overly positive self-perceptions of the majority of their peers.

However, some limitations of the current study must be taken into consideration. To begin with, only 16 children (about 12\%) from our original sample of 127 were classified as having "less positive self-perceptions." The small size of the less positive self-perception group restricted the opportunities to explore interaction effects with gender. An original sample of at least 250 children would likely be required to produce a large enough group to properly explore such questions.

It would be helpful in future studies to include sociometric ratings of peer rejection. Also, more detailed observations of children's behaviors with peers are warranted. For example, this could include the types of social initiations made and received by peers, as well as the outcomes associated with these attempts. Finally, a more detailed assessment of parenting is necessary, specifically in terms of "support and approval." This construct has been shown to be an excellent predictor of positive self-worth in older children (see Harter, 1998). A more thorough assessment of parenting would also allow for the exploration of the interaction between relations with peers and relations with parents in the prediction of selfperceptions. For example, it may be that positive relations with parents serve as a protective factor in the development of self-worth among children who experience poorer quality relations with peers. Moreover, the use of longitudinal designs will allow for a better understanding of the longer-term implications of poorer self-perceptions in early childhood.

\section{ACKNOWLEDGMENTS}

This research was supported by a Social Science Research Council of Canada (SSHRC) grant to author Coplan. The authors wish to thank Mandy Armer, Katherine Davidson, Kim O’Neil, Kavita Prakash, Andrea Schwartz, and Sandra Zimmerman for their help in the collection and coding of data.

\section{REFERENCES}

Asendorpf, J. (1993). Beyond temperament: A two-factor coping model of the development of inhibition during childhood. In K. H. Rubin \& J. Asendorpf (Eds.), Social withdrawal, inhibition, and shyness in childhood (pp. 265-290). Hillsdale, NJ: Erlbaum.

Asher, S. R., Parkhurst, J. T., Hymel, S., \& Williams, G. A. (1990). Peer rejection and loneliness in childhood. In S. R. Asher \& J. D. Coie (Eds.), Peer rejection in childhood (pp. 253-273). New York: Cambridge University Press.

Asher, S. R., \& Wheeler, V. A. (1985). Children's loneliness: A comparison of rejected and neglected peer status. Journal of Consulting and Clinical Psychology, 53, 500-505.
Barron, A. P., \& Earls, F. (1984). The relation of temperament and social factors to behavior problems in three-year-old children. Journal of Child Psychology and Psychiatry, 25, 23-33.

Baumrind, D. (1978). Reciprocal rights and responsibilities in parentchild relations. Journal of Social Issues, 34, 179-196.

Baumrind, D. (1989). The permanence of change and the impermanence of stability. Human Development, 32, 187-195.

Baumrind, D. (1997). Necessary distinctions. Psychological Inquiry, 8, 176-182.

Boivin, M., \& Begin, G. (1989). Peer status and self-perceptions among early elementary school children: The case of rejected children. Child Development, 60, 591-596.

Boivin, M., \& Hymel, S. (1997). Peer experiences and social selfperceptions: A sequential model. Developmental Psychology, 33, $135-145$.

Bowlby, J. (1969). Attachment and loss: Vol 1: Attachment. New York: Basic Books.

Bugental, D. B., \& Goodnow, J. G. (1998). Socialization processes. In N. Eisenberg (Vol. Ed.), Handbook of Child Psychology. Vol. 3: Social, emotional, and personality development (pp. 389-462). New York: Wiley.

Byrne, B. M. (1996). Measuring self-concept across the life-span. Washington, DC: American Psychological Association.

Carson, D. K., \& Bittner, M. T. (1994). Temperament and school-aged children's coping abilities and responses to stress. The Journal of Genetic Psychology, 155, 289-302.

Cassidy, J. (1988). Child-mother attachment and the self in six-year-olds. Child Development, 59, 121-134.

Cassidy, J., \& Asher, S. R. (1992). Loneliness and peer relations in young children. Child Development, 63, 350-365.

Cole, D. A., Jacquez, F. M., \& Maschman, T. L. (2001). Social origins of depressive cognitions: A longitudinal study of self-perceived competence in children. Cognitive Therapy and Research, 25, 377395.

Cooley, C. H. (1902). Human nature and the social order. New York: Charles Schribner's Sons.

Coopersmith, S. (1967). The antecedents of self-esteem. San Francisco: W.H. Freeman.

Coplan, R. J., \& Armer, M. (in press). 'Talking yourself out of being shy': Shyness, expressive vocabulary, and adjustment in preschool. Merrill-Palmer Quarterly.

Coplan, R. J., Bowker, A., \& Cooper, S. (2003). Parenting stress, child temperament, and social adjustment in preschool. Early Childhood Research Quarterly, 18, 376-395.

Coplan, R. J., Hastings, P. D., Lagace-Seguin, D. G., \& Moulton, C. E. (2002). Authoritative and authoritarian mothers' parenting goals, attributions, and emotions across different childrearing contexts. Parenting: Science and Practice, 2, 1-26.

Damon, W., \& Hart, D. (1982). The development of self-understanding from infancy through adolescence. Child Development, 53, 841864.

Darling, N., \& Sternberg, L. (1993). Parenting style as context: An integrative model. Psychological Bulletin, 113, 487-496.

Edens, J. F. (1999). Aggressive children's self-systems and the quality of their relationship with significant others. Aggression and Violent Behavior, 4, 151-177.

Evans, M. A., \& Wodar, S. (1997). Maternal sensitivity to vocabulary development in specific language-impaired and language-normal preschoolers. Applied Psycholinguistics, 18, 243-256.

Fantuzzo, J. W., McDermott, P. A., Manz, P. H., Hampton, V. R., \& Burdick, N. A. (1996). The pictorial scale of perceived competence and social acceptance: Does it work with low-income urban children? Child Development, 67, 1071-1084.

Fischer, K. W. (1980). A theory of cognitive development: The control and construction of hierarchies of skills. Psychological Review, 87, 477-531.

Fischer, K. W., Hand, H. H., Watson, M. W., Van Parys, M., \& Tucker, J. (1984). Putting the child into socialization: The development of social categories in preschool children. In L. Katz (Ed.), Current 
topics in early childhood education (Vol. 5, pp. 27-72). Norwood, NJ: Ablex.

Fordham, K., \& Stevenson-Hinde, J. (1999). Shyness, friendship quality, and adjustment during middle childhood. Journal of Child Psychology and Psychiatry, 40, 757-768.

Gardner, M. F. (1990). Expressive One-Word Picture Vocabulary Test: Revised, Manual. Novato, CA: Academic Therapy Publications.

Graybill, D. (1978). Relationship of maternal child-rearing behaviors to children's self-esteem. Journal of Psychology, 100, 45-47.

Griffin, S. (1992). Structural analysis of the development of their inner world: A neo-structural analysis of the development of intrapersonal intelligence. In R. Case (Ed.), The mind's staircase. Hillsdale, NJ: Erlbaum.

Harter, S. (1990). Causes, correlates and the functional role of selfworth: A life-span perspective. In R. J. Sternberg \& J. Kolligan (Eds.), Competence considered (pp. 67-97). New Haven, CT: Yale University Press.

Harter, S. (1996). Developmental changes in self-understanding across the 5 to 7 year shift. In A. Sameroff \& M. Haith (Eds.), Reason and responsibility: The passage through childhood (pp. 204-236). Chicago: University of Chicago Press.

Harter, S. (1998). The development of self-representations. In W. Damon (Series Ed.) \& N. Eisenberg (Vol. Ed.), Handbook of child psychology: Vol 3. Social, emotional, and personality development (5th ed., pp. 553-617). New York: Wiley.

Harter, S. (1999). The construction of the self: A developmental perspective. New York: Guilford.

Harter, S., \& Jackson, B. K. (1993). Young adolescents' perceptions of the link between low self-worth and depressed affect. Journal of Early Adolescence, 33, 383-407.

Harter, S., Marold, D. B., \& Whitesell, N. R. (1992). A model of psychological risk factors leading to suicidal ideation in young adolescents. Development and Psychopathology, 4, 167-188.

Harter, S., \& Pike, R. (1984). The pictorial scale of perceived competence and social acceptance for young children. Child Development, 55, 1969-1982.

Heatherton, T. F., \& Baumeister, R. F. (1991). Binge eating as escape from self-awareness. Psychological Bulletin, 100, 86-108.

Herz, L., \& Gullone, E. (1999). The relationship between self-esteem and parenting style: A cross-cultural comparison of Australian and Vietnemese Australian adolescents. Journal of Cross-Cultural Psychology, 30, 742-761.

Hughes, J. N., Cavell, T. A., \& Grossman, P. A. (1999). A positive view of self: Risk or protection for aggressive children? Development and Psychopathology, 9, 75-94.

Hymel, S., Bowker, A., \& Woody, E. (1993). Aggressive versus withdrawn unpopular children: Variations in peer and self perceptions in multiple domains. Child Development, 64, 2004-2021.

Hymel, S., Rubin, K. H., Rowden, L., \& LeMare, L. (1990). Children's peer relationships longitudinal prediction of internalizing and externalizing problems from middle to late childhood. Child Development, 61, 2004-2021.

Jambunathan, S., \& Norris, J. A. (2000). Perception of self-competence in relation to language competence among preschoolers. Child Study Journal, 30, 91-101.

Klein, S., \& Magill-Evans, J. (1998). Reliability of perceived competence measures for young school-aged children. Canadian Journal of Occupational Therapy, 65, 293-298.

Ladd, G. W., \& Burgess, K. B. (1999). Charting the relationship trajectories of aggressive, withdrawn, and aggressive/withdrawn children during early grade school. Child Development, 70, 910929.

Ladd, G. W., \& Coleman, C. C. (1997). Children's classroom peer relationships and early school attitudes: Concurrent and longitudinal associations. Early Education and Development, 8, 51-66.

Ladd, G. W., \& Profilet, S. M. (1996). The Child Behavior Scale: A teacher-report measure of young children's aggressive, withdrawn, and prosocial behaviors. Developmental Psychology, 32, 10081024.
Lamborn, S. D., Mounts, N. S., Steinberg, L., \& Dornbusch, S. M. (1991). Patterns of competence and adjustment among adolescents from authoritative, authoritarian, indulgent, and neglectful families. Child Development, 62, 1049-1065.

Maccoby, E. E., \& Martin, J. A. (1983). Socialization in the context of the family: Parent-child interaction. In P. H. Mussen (Ed.) \& E. M. Hetherington (Vol. Ed.), Handbook of child psychology: Vol. 4. Socialization, personality and social development (4th ed., pp. 1101). New York: Wiley.

Marsh, H. W., Craven, R. G., \& Debus, R. (1991). Self-concepts of young children 5 to 8 years of age: Measurement and multidimensional structure. Journal of Educational Psychology, 83, 377-392.

Marsh, H. W., Ellis, L. A., \& Craven, R. G. (2002). How do preschool children feel about themselves? Unravelling measurement and multidimensional self-concept structure. Developmental Psychology, 38, 376-393.

McNeilly-Choque, M. K., Hart, C. H., Robinson, C. C., Nelson, L. J., \& Olsen, S. F. (1996). Overt and relational aggression on the playground: Correspondence among different informants. Journal of Research in Childhood Education, 11, 47-67.

Mead, G. H. (1925). The genesis of the self and social control. International Journal of Ethics, 35, 251-273.

Mead, G. H. (1934). Mind, self, and society. Chicago: University of Chicago Press.

Minde, K. (1992). Aggression in preschoolers: Its relation to socialization. Journal of the American Academy of Child and Adolescent Psychiatry, 31, 853-862.

Mize, J., \& Pettit, G. S. (1997). Mothers' social coaching, mother-child relationship style, and children's peer competence: Is the medium the message? Child Development, 68, 312-332.

Parish, T. S., \& McCluskey, J. J. (1992). The relationship between parenting styles and young adults' self-concepts and evaluations of parents. Adolescence, 27, 915-918.

Patterson, C. J., Kupersmidt, J. B., \& Griesler, P. C. (1990). Children's perceptions of self and of relationship with others as a function of sociometric status. Child Development, 61, 1335-1349.

Piaget, J. (1932). The moral judgment of the child. Oxford: Harcourt Brace.

Qualter, P., \& Munn, P. (2002). The separateness of social and emotional loneliness in childhood. Journal of Child Psychology and Psychiatry, 43, 233-244.

Robinson, C. C., Mandleco, B., Olsen, S. F., \& Hart, C. H. (1995). Authoritative, authoritarian, and permissive parenting practices: Development of a new measure. Psychological Reports, 77, 819830.

Robinson, C. C., Mandleco, B., Olsen, S. F., \& Hart, C. H. (2001). The Parenting Styles and Dimensions Questionnaire (PSDQ). In B. F. Perlmutter, J. Touliatos, \& G. W. Holden (Eds.), Handbook of family measurement techniques: Vol. 3. Instruments \& index (pp. 319321). Thousands Oaks, CA: Sage.

Rubin, K. H. (1985). Socially withdrawn children: An "at risk" population? In B. H. Schneider, K. H. Rubin, \& J. E. Ledingham (Eds.), Peer relationships and social skills in childhood: Issues in assessment and training (pp. 125-139). New York: Springer-Verlag.

Rudolph, K. D., Hammen, C., \& Burge, D. (1995). Cognitive representations of self, family, and peers in school-age children: Links with social competence and sociometric status. Child Development, 66 , $1385-1402$

Rutter, M. (1987). Psychosocial resilience and protective mechanisms. American Journal of Orthopsychiatry, 57, 316-330.

Siegler, R. S. (1991). Children's thinking (2nd ed.). Englewood Cliffs, NJ: Prentice-Hall.

Steinberg, L., Lamborn, S. D., Darling, N., Mounts, N. S., \& Dornbusch, S. M. (1994). Over-time changes in adjustment and competence among adolescents from authoritative, authoritarian, indulgent, and neglectful families. Child Development, 65, 754-770.

Stipek, D., Recchia, S., \& McClintic, S. (1992). Self-evaluation in young children. Monographs of the Society for Research in Child Development, 57(1, Serial No. 226). 
Terrell-Deutsch, B. (1999). The conceptualization and measurement of childhood loneliness. In K. J. Rotenberg \& S. Hymel (Eds.), Loneliness in childhood and adolescence (pp. 11-33). New York: Cambridge University Press.

Thomas, A., \& Chess, S. (1977). Temperament and development. New York: Brunner/Mazel.

Ukrainetz, T. A., \& Blomquist, C. (2002). The criterion validity of four vocabulary tests compared to a language sample. Child Language Teaching and Therapy, 18, 59-78.

Verschueren, K., Buyck, P., \& Marcoen, A. (2001). Self-representations and socioemotional competence in young children: A 3-year longitudinal study. Developmental Psychology, 37, 126-134.

Verschueren, K., \& Marcoen, A. (1999). Representation of self and socioemotional competence in kindergartners: Differential and combined effects of attachment to mother and father. Child Development, 70, 183-201.
Verschueren, K., Marcoen, A., \& Schoefs, V. (1996). The internal working model of the self, attachment, and competence in five-year-olds. Child Development, 67, 2493-2511.

Wiesner, M., \& Beer, J. (1991). Correlations among WISC-R IQs and several measures of receptive and expressive language for children referred for special education. Psychological Reports, 69, 10091010.

Wu, P., Robinson, C. C., Yang, C., Hart, C. H., Olsen, S. F., \& Porter, C. L., et al. (2002). Similarities and differences in mothers' parenting of preschoolers in China and the United States. International Journal of Behavioral Development, 26, 481-491.

Younger, A. J., Gentile, C., \& Burgess, K. B. (1993). Children's perceptions of social withdrawal: Changes across age. In K. Rubin \& J. Asendorpf (Eds.), Social withdrawal, inhibition, and shyness in childhood (pp. 215-235). Hillsdale, NJ: Erlbaum. 